\title{
Extracorporeal Lung Support and Continuous Renal Replacement Therapy In-Series Combination: The Role of High Cut-Off Membranes
}

\author{
Guglielmo Consales Lucia Zamidei Giuliano Michelagnoli \\ Department of Anaesthesia and Critical Care, Santo Stefano Hospital, Prato, Italy
}

Extracorporeal lung support (ECLS)/ continuous renal replacement therapy (CRRT) combination is frequently used in treating acute kidney injury (AKI) associated to acute respiratory distress syndrome (ARDS). In this context, some authors argue against the in-series ECLS/CRRT combination [1] because this association should prohibit the use of regional anticoagulation and should exacerbate cytokines release which in turn provokes hemolysis and disseminated intravascular coagulation. Nevertheless, the use of a separate CRRT device imposes the positioning of an independent central line. Furthermore, single dual-lumen cannulae are often employed for ECLS, and additional venous access should be reserved for a step-up to a double cannulae approach [2].

We report the use of in-series ECLS/ CRRT in 4 ARDS patients with AKI admitted to the multidisciplinary intensive care unit of the Prato Hospital, Italy, where about 100 CRRTs and 10 ECLSs are performed per year. Data were collected be- tween January 2015 and December 2015; we obtained informed consent prior to retrospective analysis inclusion. ECLS was provided by Novalung iLA-Activve ${ }^{\mathrm{TM}}$, a veno-venous pump-driven 'mid blood flow range' (up to 2.5 litres/min) extracorporeal $\mathrm{CO}_{2}$ removal system. Continuous veno-venous hemodialysis with high cutoff membrane (HCOm) specifically addressed to eliminate circulating cytokines (SepteX ${ }^{\mathrm{TM}}$, Gambro Dialysatoren, Germany) was performed with PrismafleX-eXeed ${ }^{\mathrm{TM}}$ System (Gambro-Lundia, Sweden). CRRT was connected to the venous line of the doublelumen $27 \mathrm{~cm} / 24 \quad \mathrm{~F}$ femoral cannula (Novaport $^{\mathrm{TM}}$ twin, Novalung, Germany), distally to $\mathrm{iLa}^{\mathrm{TM}}$ membrane and flow sensor. Patients were treated with systemic heparinization aiming to double aPTT. All patients survived and days of combined ECLS/CRRT treatment were 5, 9, 11, 9, respectively. We did not register alarms related to air bubbles, pressure abnormalities or clotting of both ECLS and CRRT devic- es; moreover, no complications related to anticoagulation were recorded. In all the patients, the CRRT circuits were changed each $48 \mathrm{~h}$ and any inadvertent pressure variation in the ECLS circuit was avoided positioning 2 three-way-stopcocks in the CRRT connectors. Although we did not routinely dose cytokines and free hemoglobin levels/clearance, we observed a significant reduction of C-reactive protein and procalcitonin associated to no signs of intravascular hemolysis and amelioration of organ dysfunction parameters (table 1).

It should be highlighted that cytokines storm is a hallmark of ARDS and sepsis, being 'per se' a cornerstone of their pathophysiology. At this regard, blood purification has been proposed in order to remove circulating cytokines. Among these techniques, the use of HCOm-CRRT is associated with high degree of elimination of systemic mediators. This higher clearance is due to the increase in the membrane pore size that allows the removal of cyto-

\section{KARGER}

E-Mail karger@karger.com

www.karger.com/bpu (c) 2016 S. Karger AG, Base

0253-5068/16/0424-0304\$39.50/0
Guglielmo Consales

Department of Anaesthesia and Intensive Care Santo Stefano Hospital

Via Suor Niccolina Infermiera 1, IT-59100 Prato (Italy)

E-Mail gconsales@gmail.com 


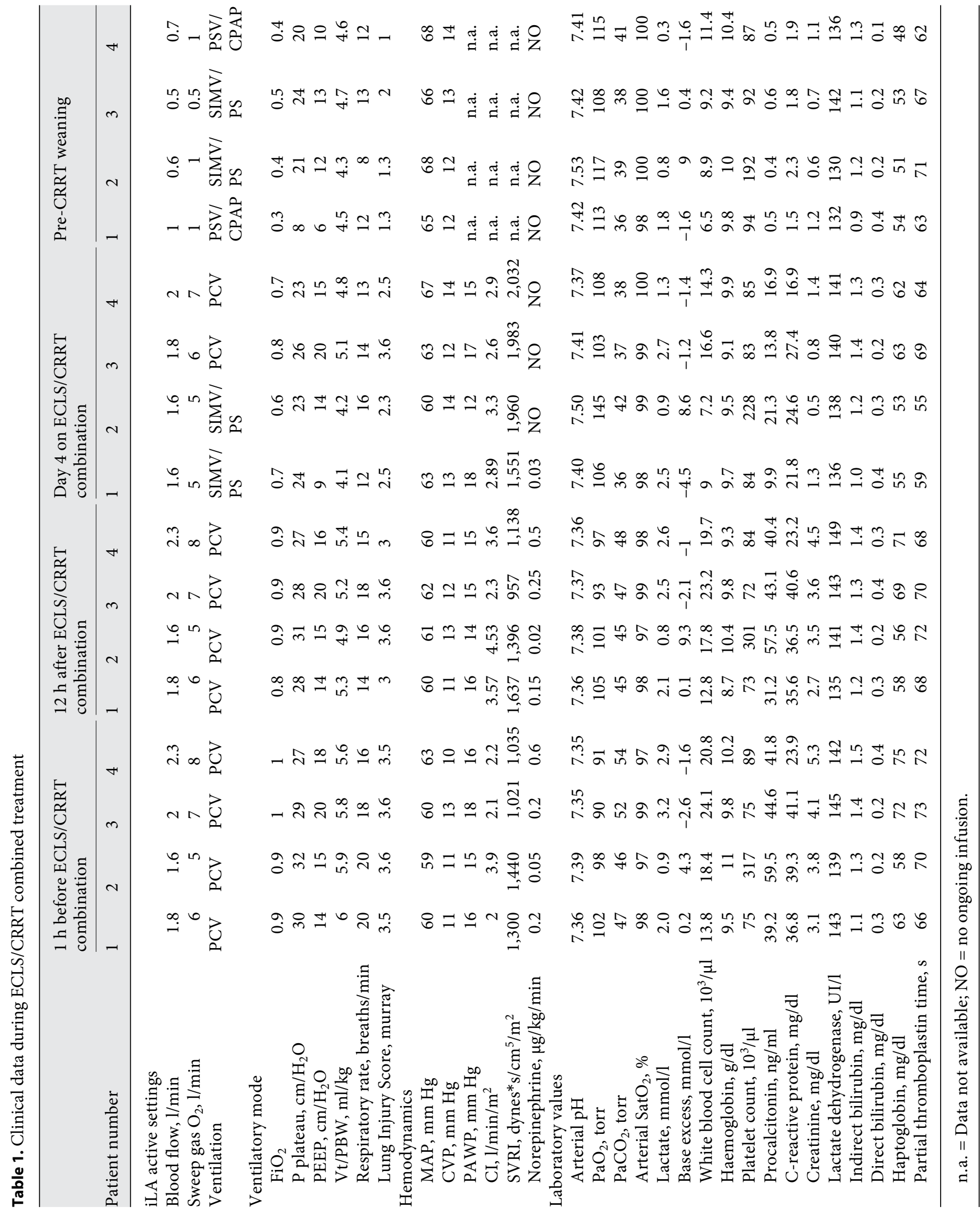


kines up to $60 \mathrm{kDa}$ [3]. ECLS/HCOmCRRT was demonstrated to be beneficial in a porcine model in determining increased elimination of cytokines [4]. Moreover, although hemolysis is a general side effect of all extracorporeal therapies, a recent in vitro study demonstrated the highest cell-free plasma hemoglobin removal capacity of SepteX ${ }^{\mathrm{TM}}$ (Gambro Di- alysatoren, Germany), a specifically designed HCOm compared to standard membrane [5].

In conclusion, knowing that HCOm enhances the clearance of inflammatory mediators released during ARDS and potentially increased by the extracorporeal circuit, we used ECLS/HCOm-CRRT in series association with safe and effective results.

\section{Acknowledgment}

None.

\section{Disclosure Statement}

None.

\section{References}

1 Jacobs R, Honore PM, Spapen HD: Intertwining extracorporeal membrane oxygenation and continuous renal replacement therapy: sense or nonsense? Crit Care 2015;19: 145.

2 Seczynska B, Krolikowski W, Nowak I, et al: Continuous renal replacement therapy during extracorporeal membrane oxygenation in

patients treated in medical intensive care unit: technical considerations. Ther Apher Dial 2014;18:523-534.

3 Villa G, Zaragoza JJ, Sharma A, et al: Cytokine removal with high cut-off membrane: review of literature. Blood Purif 2014;38:167-173.

4 Shi J, Chen Q, Yu W, et al: Continuous renal replacement therapy reduces the systemic and pulmonary inflammation induced by venovenous extracorporeal membrane oxygenation in a porcine model. Artif Organs 2014;38: 215-223.

5 Hulko M, Kunz M, Yildirim M, et al: Cell-free plasma hemoglobin removal by dialyzers with various permeability profiles. Sci Rep 2015;5: 163-167. 